\title{
Delayed bowel perforation after instilling over warmed peritoneal dialysate
}

\author{
Xueli Lai ${ }^{1}$, Mingming $\mathrm{Nie}^{2}$, Xiaodong $\mathrm{Xu}^{3}$, Yuanjie Chen ${ }^{4}$ and Zhiyong Guo ${ }^{1^{*}}$ (D)
}

\begin{abstract}
Background: Peritoneal dialysis (PD) is a safe and home-based treatment for end-stage renal disease (ESRD) patients. The direct thermal damage of abdominal organs is very rare.

Case presentation: We report a peritoneal dialysis patient presented abdominal pain and feculent effluent 3 weeks after he instilled hot dialysis solution. In spite of emergency exploratory laparotomy and active treatment, the patient died of septic shock. Biopsy revealed necrosis and perforation of the intestines.

Conclusions: Delayed bowel perforation by hot fluid is very rare. Standardized performance is of the first importance for peritoneal dialysis patients.
\end{abstract}

Keywords: Peritoneal dialysis, Perforation, Thermal damage, Case report

\section{Background}

Peritoneal dialysis (PD) is one of the important kidney replacement treatments of end-stage renal disease patients, which is a safe, convenient and home-based treatment. Patient education is crucial, because any nonstandard operating steps may result in various complications. Bowel perforation is an uncommon but serious complication of PD. We report a case of delayed perforation of the small bowel after instilling hot peritoneal fluid. To our knowledge, there have been no previous reports of thermal bowel damage caused by dialysis solution.

\section{Case presentation}

A 63-year-old man was admitted to our hospital complaining that he presented abdominal pain and feculent effluent. He was hospitalized for uremia treated with peritoneal dialysis 5 years ago. The possible reason for uremia was chronic glomerulonephropathy, and the renal biopsy was not performed. He remained on

\footnotetext{
* Correspondence: drguozhiyong@163.com

'Department of Nephrology, Shanghai Changhai Hospital, 168 Changhai Road, Shanghai 200433, P.R. China

Full list of author information is available at the end of the article
}

continuous ambulatory peritoneal dialysis without complications for 5 years till he instilled hot dialysis solution, which was heated in a microwave oven on high for 5 min by his new caretaker in a nursing home 3 weeks before. (The caretaker was a fresh man and came from a nursing home without enough education and training of peritoneal dialysis.)The patient went to the emergency room immediately because of severe abdominal pain. There was no signs of bowel perforation and peritonitis. No abnormality was found in abdominal $\mathrm{X}$ ray and complete blood count. The peritoneal fluid culture was sent. He was asked to fast for 5 days and administered with preventive antibacterial treatment. Meanwhile he ceased peritoneal dialysis and was converted to nonheparin hemodialysis. The abdominal pain relieved and the peritoneal drainage was clear, so he asked for being discharged from the hospital on the second day against medical advice. After 3 days, the microbiological analysis of the peritoneal fluid revealed growth of Enterococcus faecium. He was treated with intravenous (IV) fluids and antibiotics in the emergency room of another hospital. After 10 days of IV treatment, he felt pain in the abdomen again and feculent effluent was found in the peritoneal catheter. He was readmitted to our hospital. 
Examination on admission indicated that he was afebrile and had a soft tender abdomen. Blood examination showed white blood cell count $21.88 \times 10^{9} / \mathrm{l}$, hemoglobin $72 \mathrm{~g} / \mathrm{l}$, neutrophil count $19.89 \times 10^{9} / \mathrm{l}$. Abdominal computed tomography (CT) showed peri-hepatic pneumatosis and effusion. No free air or dilated loops of bowel were seen. The patient underwent emergency exploratory laparotomy. A great mount of pus mosses and fecal fluid were found in the abdominal cavity and between intestines. There were multiple perforation holes on the small bowel (the largest one $4 * 3 \mathrm{~cm})$ and a single perforation $\left(1^{*} 1 \mathrm{~cm}\right.$ ) on the anterior rectum wall. A section of the small bowel was resected (Figs. 1 and 2). Other perforation holes were repaired and ileostomy was performed. The peritoneal catheter was removed. The peritoneal cavity was lavaged with copious amounts of saline solution. The patient developed intestinal fistula after the surgery. Parenteral nutrition, anti-infection treatment and continuous renal replacement therapy (CRRT) were applied. The patient died of septic shock 15 days later.

\section{Discussion and conclusion}

Delayed bowel perforation is an uncommon complication of PD [1]. The peritoneal catheter is believed to be a major risk factor due to its ability to cause erosion or perforation of hollow viscera [2]. To our knowledge, there have been no reports of bowel perforation caused by hot dialysate nor reports of organ damage due to direct exposure to hot dialysate or hot water.

In fact, the small intestinal mucosa is very susceptible to warm ischemia even after short duration. Gastrointestinal perforation, abscess formation and sepsis resulting from thermal injury were reported in percutaneous

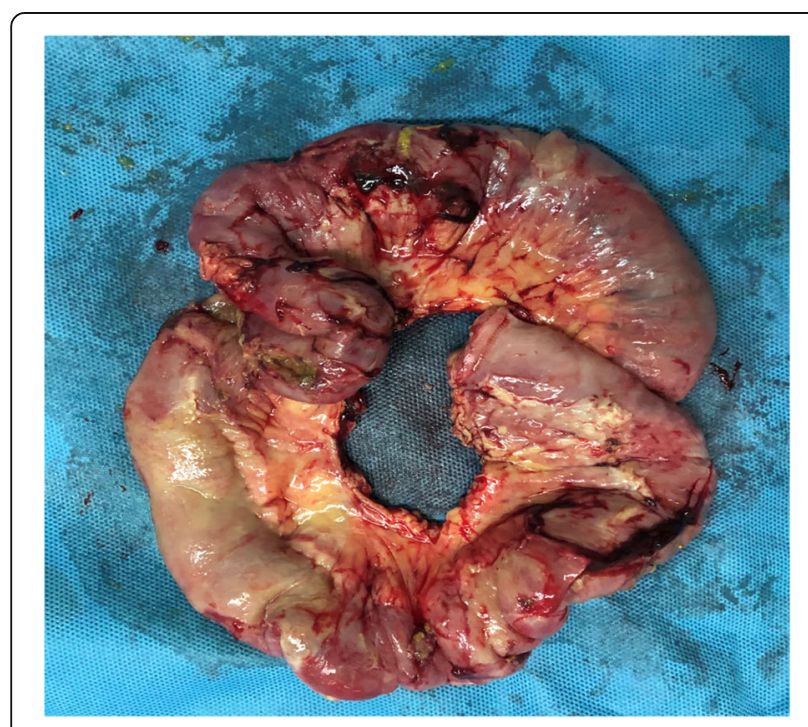

Fig. 1 Gross view of the necrotic small bowel: $33 \mathrm{~cm}$ of which the largest perforation hole was in the middle

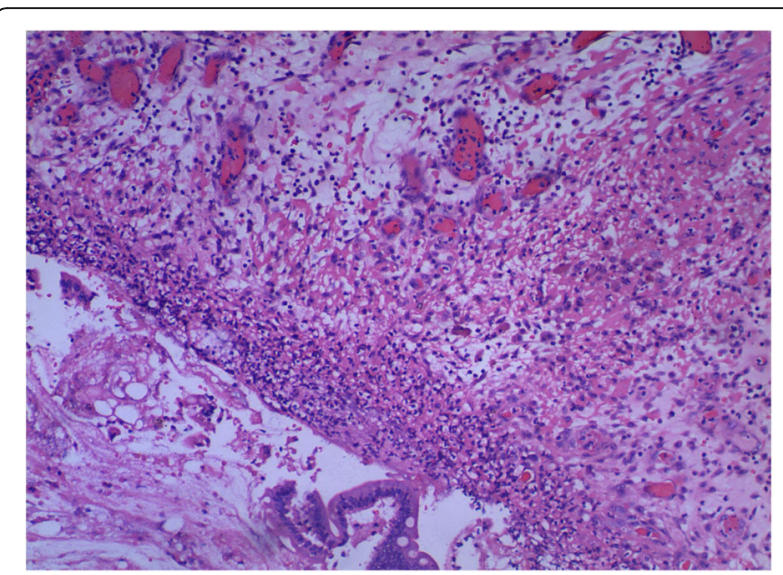

Fig. 2 Histologic findings of the small bowel showing hemorrhagic necrosis and neutrophil infiltration of the full-thickness bowel around the largest hole. [hematoxylin and eosin (H\&E) stain; original magnification $\times 100]$

radiofrequency ablation (PRFA) of hepatic tumor [3] and renal tumor [4]. In another case, a substantial amount of heat created by electrosurgical instruments during surgical operations has been shown to spread throughout the tissue, leading to unintended thermal damage [5].

The development of tissue damage depends on both temperature and the duration of heat exposure [6]. It is believed that increasing the temperature of the tissue to $>45^{\circ} \mathrm{C}$ may lead to irreversible tissue change [7]. To explore the temperature of the dialysate the patient instilled, we repeated the heating course and found that the temperature of peritoneal dialysis solution after heating was up to $80^{\circ} \mathrm{C}$. Although there were none typical clinical manifestations of bowel perforation during the few post-instilling days, we believe that the thermal injury was lasting and deteriorated, resulting in delayed perforation.

The degree of intestinal tissue injury was evaluated using a grading scale from 0 to 8 . Grade 0 is defined as normal mucosa. In grade 1 to 3 , the subepithelial space of the villi is increasing. Grade 4 is characterized by denuded of the villi, and grade 5 by loss of the villi. The intestinal crypt layer is injured in grade 6 , and the entire intestinal mucosa is necrotic in grade 7 [8]. Grade 8 symbolizes transmural infarction. Histological examination of a surgical specimen in our case revealed fullthickness injury including coagulation necrosis and hemorrhage congestion.

In this case, the immediate surgery and early effective anti-infective therapy might be helpful once the peritoneal fluid culture was positive. However, the diagnosis was delayed rendering treatment difficult and complicated because of the delayed perforation. On the other hand, we are greatly convinced that prevention is better than cure for cases like this. No matter how much 
emphasis we put on the importance of patient education, it cannot be overstated.

At the meantime, we took measures to prevent such incident from happening again. Firstly, our staff called to each PD patient and his/her relative or caretaker to emphasize that peritoneal dialysate must not be warmed by any other devices except a fixed warmer, which is the essential part of PD training. Secondly, for new patients on PD, we extend the training period and make sure they perform peritoneal dialysis repeatedly and correctly. For outpatients and inpatients, we reinforce reeducation and retraining on peritoneal dialysis as much as possible. Thirdly, we contacted with PD solution Dianeal manufacturers and suggest they should highlight the caution of correct heating procedure on the PD bag. Meanwhile, we call for a sound old-age security mechanism, in which caretakers in the nursing home should be trained with professional knowledge and skills for before they need to take care of the elderly suffering from special diseases.

In conclusion, delayed bowel perforation by overly warm fluid is very rare. Standardized performance is of the first importance for peritoneal dialysis patients. Repeated propaganda and education for PD patients is needed.

\section{Abbreviations}

PD: Peritoneal dialysis; ESRD: End-stage renal disease; IV: Intravenous; $\mathrm{CT}$ : Computed tomography; CRRT: Continuous renal replacement therapy; PRFA: Percutaneous radiofrequency ablation

\section{Acknowledgements}

We would like to thank all the medical staff involved in the rescue of the PD patient.

\section{Authors' contributions}

XLL wrote the first draft of the manuscript. MMN and XDX performed the exploratory laparotomy. XLL, YJC and ZYG were involved in clinical management of the patient. All authors have read and approved the manuscript.

\section{Funding}

This work was supported by grants from the National Natural Science Foundation of China (No.81770763 and No. 81800678), Shanghai Science and Technology Innovation Fund (No.18441905900) and Discipline Grant from Shanghai Changhai Hospital (No. 2020YXK041).

\section{Availability of data and materials}

If required, the relevant material can be provided by corresponding author on reasonable request.

\section{Declarations}

\section{Ethics approval and consent to participate}

Not applicable.

\section{Consent for publication}

The patient' wife has given written informed consent, obtained by the first author, to publish data and the image.

\section{Competing interests}

The authors have no conflicts of interest to declare.

\section{Author details}

'Department of Nephrology, Shanghai Changhai Hospital, 168 Changhai Road, Shanghai 200433, P.R. China. ${ }^{2}$ Department of Gastroenterology, Shanghai Changhai Hospital, 168 Changhai Road, Shanghai 200433, P.R.

China. ${ }^{3}$ Department of Colorectal Surgery, Shanghai Changhai Hospital, 168 Changhai Road, Shanghai 200433, P.R. China. ${ }^{4}$ Intensive Care Unit, Shanghai Changhai Hospital, 168 Changhai Road, Shanghai 200433, P.R. China.

Received: 11 January 2021 Accepted: 8 April 2021

Published online: 20 April 2021

\section{References}

1. Wang RD, Chen ZM, Wang JX, Zhang XH, Shou ZF, Chen JH. Delayed bowel perforation in a peritoneal dialysis patient: a case report and literature review. Perit Dial Int. 2014;34(4):460-6. https://doi.org/10.3747/pdi.2012.0034 5.

2. Bustos E, Rotellar C, Mauoni MJ, Rakowski TA, Argy WP, Winchester JF. Clinical aspects of bowel perforation in patients undergoing continuous ambulatory peritoneal dialysis. Semin Dial. 1994;7(5):355-9.

3. Livraghi T, Luigi S, Franca Meloni M, Scott Gazelle G, Halpern EF, Goldberg SN. Treatment of focal liver tumors with percutaneous radio-frequency ablation: complications encountered in a multicenter study. Radiology. 2003;226(2):441-51. https://doi.org/10.1148/radiol.2262012198.

4. Johnson DB, Solomon SB, Su LM, Matsumoto ED, Kavoussi LR, Nakada SY, et al. Defining the complications of cryoablation and radio frequency ablation of small renal tumors: a multi-institutional review. J Urol. 2004; 172(3):874-7. https://doi.org/10.1097/01.ju.0000135833.67906.ec.

5. Dodde RE, Gee JS, Geiger JD, Shih AJ. Monopolar electrosurgical thermal management for minimizing tissue damage. IEEE Trans Biomed Eng. 2012;9: $167-73$.

6. Egglestone JL, von Maltzahn WW. Electrosurgical devices. In: Bronzino Joseph D, editor. The biomedical engineering handbook. 2nd ed. Boca Raton: CRC Press; 2000.

7. Kojima S, Sakamoto T, Honda M, Nishiguchi R, Ogawa F. Rare complication after totally extraperitoneal endoscopic inguinal hernia repair: small bowel perforation without peritoneal disruption. Asian J Endosc Surg. 2016;9(4): 311-3. https://doi.org/10.1111/ases.12294.

8. Park PO, Haglund U. Regeneration of small bowel mucosa after intestinal ischemia. Crit Care Med. 1992;20(1):135-9. https://doi.org/10.1097/0000324 6-199201000-00026

\section{Publisher's Note}

Springer Nature remains neutral with regard to jurisdictional claims in published maps and institutional affiliations.
Ready to submit your research? Choose BMC and benefit from:
- fast, convenient online submission
- thorough peer review by experienced researchers in your field
- rapid publication on acceptance
- support for research data, including large and complex data types
- gold Open Access which fosters wider collaboration and increased citations
- maximum visibility for your research: over $100 \mathrm{M}$ website views per year
At BMC, research is always in progress.
Learn more biomedcentral.com/submissions 